\title{
Development or Environmental Jeopardy: The Carbon Footprint of Hotels in Juba South Sudan
}

\author{
Ladu David Morris Lemi1 ${ }^{12 *}$, Michael Carnegie LaBelle² \\ ${ }^{1}$ School of Applied and Industrial Sciences, University of Juba, Juba, South Sudan \\ ${ }^{2}$ Department of Environmental Sciences and Policy, Central European University, Budapest, Hungary \\ Email: *ladulemison@gmail.com
}

How to cite this paper: Lemi, L. D. M., \& LaBelle, M. C. (2022). Development or Environmental Jeopardy: The Carbon Footprint of Hotels in Juba South Sudan. American Journal of Climate Change, 11, 1-21. https://doi.org/10.4236/ajcc.2022.111001

Received: October 7, 2021

Accepted: February 14, 2022

Published: February 17, 2022

Copyright $\odot 2022$ by author(s) and Scientific Research Publishing Inc. This work is licensed under the Creative Commons Attribution International License (CC BY 4.0).

http://creativecommons.org/licenses/by/4.0/

\begin{abstract}
Climate change and global warming have been identified as major threats to the development of South Sudan due to greenhouse gases (GHGs) emission responsible for the rising temperatures and erosion of existing ecosystem services that support local livelihoods. Mitigating GHGs emissions has become an urgent global policy trajectory with countries acceding to related Treaties and setting national targets. Despite having submitted its initial communications to the United Nations Framework Convention on Climate Change (UNFCCC), outlining specific sectors for GHGs reduction, the rapidly growing hotel industry has not been identified among the sectors and no GHGs emission reporting has been undertaken. Therefore, this study aimed to assess, quantify and report on the GHGs emission potential of the hotel industry in Juba-South Sudan, examine existing GHGs emission reporting mechanisms and propose a reporting framework. Using a standard quantitative methodology, the carbon footprint of twenty-seven hotels was assessed. The results showed that the hotel industry is one of the leading emitters of GHGs emission amounting to 14,624.9-ton $\mathrm{CO}_{2}$ eq/year. The study also found no existing GHGs reporting systems in South Sudan and proposed a reporting framework and identified potential emissions reduction strategies for the hotel industry to deal with climate change and carbon emission issues of the hospitality industry. It recommends that further research be initiated to 1) assess the applicability of the identified strategies in the context of South Sudan and 2) to quantify GHGs emissions from cooling appliance within the hospitality industry as well as emissions from other growing sectors like the transportation.
\end{abstract}

\section{Keywords}

Carbon Footprint, Hotel, Climate Change, GHG Emission, Reporting Mechanism 


\section{Introduction}

The impact of climate change and global warming has become one of the contemporary challenges facing humanity. Greenhouse Gas (GHG) emissions from both natural and anthropogenic sources such as natural disasters and human economic activities are largely responsible for the rising temperatures and sea levels (Montoya-Torres et al., 2014; Abeydeera \& Karunasena, 2019a). Given the growing body of evidence on the relationship between GHG emissions and global warming, the demand to reduce carbon emissions has become an urgent global policy trajectory to halt the negative impacts of climate change on economies, health, and societal well-being due to environmental degradation and loss of ecosystem services (Abeydeera et al., 2019). At the global level, the adoption and ratification of Multilateral Environmental Agreements (MEAs) such as the Paris Agreement, the United Nations Framework Convention on Climate Change (UNFCCC), and the Kyoto Protocol are one of the indicators that countries are committed to taking actions to reduce GHG emissions by setting national and regional priorities and reduction targets (Güereca et al., 2013).

In South Sudan, climate change has been identified as a major threat to the socio-economic development of the country. Studies indicate that South Sudan is one of the most rapidly warming places on earth with temperatures increasing by $0.4^{\circ} \mathrm{C}$ per decade; a rise that is two and half times higher than the global average (USAID, 2016). Yet, climate data on GHGs emissions for South Sudan is currently unavailable. As the newest member of the United Nations, the participation of South Sudan in global MEAs to tackle pressing environmental issues is limited. However, in 2014, the country acceded to the United Nations Convention to Combat Desertification (UNCCD) and UNFCCC. In response to the requirements of the Kyoto protocol, it prepared and submitted its Intended Nationally Determined Contribution (INDC) and National Adaptation Plan of Action (NAPA) which outlined national emissions reduction measures and priority sectors, including land use, land-use change, and forestry (LULUCF), agriculture, energy, and the transport sectors as the main sources of GHG emissions.

For a country to establish effective carbon reduction strategies, it is fundamental to quantify the carbon footprint of the concerned sectors in order to understand the sectoral GHG emission contributions to the national emission scale. Hence, the concept of carbon footprint has gained momentum in environmental science research as an important technique, which provides a better understanding of the total amount of GHGs produced directly or indirectly as a result of an activity while taking into account the different stages of a product life cycle (Padilla-Rivera et al., 2018). The application of carbon footprint analysis in climate change studies is essential because it tracks the carbon performance of an entity or a development sector for the establishment of various GHG emissions and climate change mitigation strategies 
(Gao et al., 2014).

Nevertheless, tackling climate change and achieving development are two complex but closely related challenges we face in modern times. For instance, human activities that drive development such as industrialization, agriculture, energy, and transport are the major causes of anthropogenic greenhouse gas emissions. Among the different development sectors in South Sudan, the hospitality sector is the only actively growing sector in the country with the numbers of hotels in Juba city increasing from three in 2005 to over one hundred in 2021. As reported by Cingoski and Petrevska (2018); Wang et al., (2018), and Abeydeera and Karunasena (2019a), the hotel industry is one of the most intensive energy users within the building sector globally and emits a significant amount of greenhouse gases. In its national communication to UNFCCC, South Sudan commits to undertake a national GHGs inventory for a better assessment, quantification, and development of appropriate emission reductions strategies in the identified sectors. However, the hotel industry which is rapidly growing has not been identified for carbon emission reduction.

Addressing climate change implications of the hotel industry through GHG gas emissions quantification and developing emission reduction strategies can have a positive impact on the achievement of Sustainable Development Goals (SDGs). For example, Fujimori et al., (2020) has demonstrated the sustainable development implications of climate change mitigation where they showed that $1 \%$ reduction of $\mathrm{CO}_{2}$ can avoid $0.57 \%$ of air pollution-related premature deaths (SDG3) and species richness (SDG15) can decrease by only $0.026 \%$. we argue that quantifying hotels' GHG emissions can contribute to national efforts for achieving sustainable development goals directly linked to SDG13 on climate action through cooperate awareness and disclosure of environmental impacts, SDG8 on economic growth, SDG12 focusing on waste minimization and recycling and SDG16 on mitigating climate related conflicts.

To this end, the main purpose of this study was, therefore, to assess, quantify and report on the emission potential of the hotel industry in Juba-South Sudan and propose a framework to guide hotels' management in developing GHG emissions reporting system for the sector. The findings of the study are expected to change the perception of the policymakers about the hotel industry in regard to carbon emissions and trigger the development of policy strategies towards climate-smart or green hotels development in South Sudan.

\section{Literature Review}

Climate change and global warming are terms commonly used interchangeably in environmental science discourse although they have distinct meanings. While the former refers to the long-term change in the climate or weather pattern that defines a geographical area, the latter is the long-term increase in earth temperature at the global scale (Kennedy \& Lindsey, 2015). Climate change is a recognized threat that has become one of the main topics of global debate attracting 
the attention of researchers, policymakers, governments, and corporations. Climate change is mainly caused by the emission of GHGs resulting from human activities, of which, carbon constitutes the largest portion (Kumari et al., 2018; Yoon et al., 2018). Increasing GHGs emissions and their negative impacts on global economies, environment, health, and social well-being has caused concerns worldwide. These concerns have prompted world leaders to step in with several MEAs such as the UNFCCC, Kyoto Protocol, and more recently the Paris agreement aimed at reducing GHGs emissions at all levels and achieving sustainable development.

It is now known that development activities affect the environment in different ways and scales. The building sector is among the fastest-growing industries with a significant contribution to environmental degradation and accounts for $19 \%$ to $30 \%$ of global carbon emission due to their intensive energy use (Nauclér \& Enkvist, 2009). Despite playing an important role in national economies through job creation and revenue generation, the hotel sector creates several negative environmental impacts such as waste generation, carbon emission, and unprecedented noise from events and power generation that disrupts social comfort. According to Abeydeera and Kaninasena (2019a), the hotel sector is a major contributor of GHG emission accounting for about $21 \%$ of the total tourism sector emissions; yet these emissions have gone unnoticed in many countries including South Sudan due to either failure in identifying the hospitality sector among the national priority sectors targeted for emission reduction or unavailability of established national reporting mechanism of carbon emissions (Ricaurte, 2011).

In recent years, research in hotels' carbon emission potential has attracted the attention of academics and policymakers globally. However, carbon emission from hotels in developing countries in general and Sub-Saharan Africa in particular remains disregarded even at the policy level. This limitation has made hotels managers and national authorities unable to identify hotels' GHG emission contribution. For instance, South Sudan's NAPA and INDC identified power generation, LULUCEF, agriculture, and transportation as the main sources of GHGs, while the waste and industry-related activities are considered negligible and no reference is made towards mitigating potential emissions emanating from the highly expanding hospitality sector running on self-generated electricity using onsite diesel generators (Lemi \& LaBelle, 2020).

Studies conducted by Wang et al., 2018; Pablo-Romero et al., (2017); Cingoski and Petrevska (2018) to investigate the carbon emissions potential of the hospitality sector, revealed that hotels and the accommodation sector are a key source of GHG emission, which emits thousands of tons of carbon equivalent annually and exacerbates global warming and the associated climate change. In a related study conducted in Juba-South Sudan, Lemi and LaBelle (2020) showed that private off-grid electricity generation accounts for $1553.8 \mathrm{tCO}_{2}$ eq emissions per month; yet this amount is not accounted for in South Sudan's national docu- 
ments. It is, therefore, evident that the hotel industry in South Sudan needs to be assessed for proper GHGs emissions and reporting mechanisms in line with the international standards.

The need to reduce carbon emission is urgent and it requires the involvement of everyone if we want to achieve the sustainable development goal 13 and the aim of the Paris Agreement. In order to achieve national emission targets, practitioners, policymakers, researchers and government authorities have dedicated attention towards the identification of mitigation strategies and reporting mechanisms (Zheng \& Suh, 2019; Padilla-Rivera et al., 2018; Hertwich et al., 2019). Thus, the concept of carbon footprint which tracks the carbon performance of an entity/organization has been adopted to measure an organization's contribution to climate change. To this end, this concept has gained wide recognition in carbon emission studies for the quantification of carbon emissions (Montoya-Torres et al., 2014; Padilla-Rivera et al., 2018). While some of the studies quantified carbon emissions on a global and national scale (Peters et al., 2012; Wiedmann et al., 2010), some quantified carbon emissions on a product, institutional, or town scale (Larsen et al. 2013; Aroonsrimorakot et al., 2013; Erickson et al., 2012) to influence national and global environmental strategies and policies towards carbon emission mitigation.

To achieve low carbon emissions in the hotel sector, the adoption of sustainable and climate-smart practices that address environmental issues such as waste production and related emissions arising from hotel operations is critical. This requires that the carbon emissions of hotels operations be quantified to understand how hotels' activities impact global sustainability and their carbon footprint reported appropriately (Eskerod et al., 2019; Loyarte-López et al., 2020). Several carbon footprint calculations methods and guidelines have now been developed and used in carbon emissions quantification studies. These include the Kyoto Protocol, intergovernmental panel on climate change (IPCC), International Organization for Standardization (ISO), and Life Cycle Assessment (LCA) (Abeydeera \& Karunasena, 2019a).

The ISO approach is based on the principles of the LCA methodology provided in ISO 14040-14044 which is used for the assessment of the environmental impact of products throughout their life cycles. Loyarte-López et al., (2020) also described a methodology for calculating the carbon footprint of intangible assets related to all research activities. On the other hand, Filimonau et al., (2011) described the carbon footprint of hotels using a simplified derivative of LCA called Life Cycle Energy Analysis (LCEA) as the best alternative focusing on energy and associated carbon emissions as a measure of hotels environmental impacts by converting energy use data into GHG emissions.

The carbon footprint of an institution accounts for emissions that occur within an organization's defined area. It focuses on direct (Scope 1) and indirect emissions linked to the purchased electricity from the grid (Scope 2) and other indirect emissions (scope 3) caused by different activities including transporta- 
tion of goods and staff as well as disposal of wastes (Güereca et al., 2013). In this study, however, no national grid electricity existed in Juba at the time this study was conducted. The available electricity sources were self-generation using captive diesel generators. Hence, the hotels' carbon footprint in this study was calculated based on scopes 1 and 3 .

Reporting carbon emissions for an entity is an important sustainable development indicator. The UNFCCC requires each Party to communicate to the convention their annual national inventory of anthropogenic greenhouse gas emissions using standard reporting mechanisms as a step towards reversing the global trend of climate change and associated disasters. The Kyoto protocol for instance, advocates for the reduction of greenhouse gas emission using three key economic instruments including Emission Trading (ET), Clean Development Mechanism (CDM), and Joint Implementation (JI) that countries under Annex I of the protocol can deploy at market and project levels to control emissions (Laroui, et al., 2004). Despite being incredible mechanisms for emission reduction with a boost to the economy, the implementation of these mechanisms in countries with informal energy market designs like South Sudan can be difficult (Lemi \& LaBelle, 2020). ISO 14064 and the International Sustainability and Carbon Certification (ISCC) also provide guidelines for GHG emissions reporting in the context of an organization and supply chain carbon footprint respectively. Moreover, IPCC provides further guidelines that exist in five separate volumes of which, none specifies reporting modalities for the hospitality sector.

Given this specificity gap, Ricaurte (2011) laments the absence of specific standards to guide the process of reporting hotels' GHG emissions. Hence, Abeydeera and Karunasena (2019b) proposed a framework based on the guidelines provided by the IPCC, ISO 14064, ISCC, and GEF to guide the process of GHG emission reporting for hotels, and in this study, we propose additional framework to help hotels establish their reporting mechanism from scratch.

\section{Materials and Method}

The GHG emissions inventory of any institution indicates its direct and indirect emissions that arise from the routine daily activities, represented as a single weighted value using each gas' global warming potential (GWP). This value is the carbon footprint that defines the climate change contribution of the institution. This study was conducted in Juba, the capital city of South Sudan to assess the carbon footprint of the hospitality sector with an objective to contribute to the GHG emissions reduction efforts of South Sudan through proper emissions reporting mechanisms. The GHG emissions from the hotels targeted in this study are based on the first three main gases, which include Carbon dioxide $\left(\mathrm{CO}_{2}\right)$, Methane $\left(\mathrm{CH}_{4}\right)$, and Nitrous oxide $\left(\mathrm{N}_{2} \mathrm{O}\right)$. To achieve the aims of the study, a case study approach was employed to assess the carbon emissions of Twenty-seven (27) hotels operating in Juba offering accommodation, catering, 
and conference services to their clients. The hotels were selected based on two criteria (i) their proximity to the commercial center (i.e. 0 - $2 \mathrm{~km}$ ) and their online review at a scale of 5 with a selection cutting point of 4.0. All selected hotels fall under three- and four-stars categories.

\subsection{Research Setting and Data Inventory}

The setting of the organizational boundary for the study comprised of the entire area under each hotel management. The GHG emissions were evaluated through a defined operational boundary based on the three scopes proposed by the GHG Protocol (2020), as important levels for quantifying carbon footprint. Both direct and indirect emissions sources were identified and then presented in each scope as shown in Table 1.

The inventory data was collected using a bottom-up approach where all the possible sources of emissions were first identified on the basis of ISO 14064 standard. The data used for the emission analysis was collected from the hotels' managers or their designated officers using a detailed self-administered questionnaire according to (Stewart \& Cash Jr., 2008), that captured data related to; fuel consumption for electricity generation and transportation; water supply, solid waste generation, and wastewater on a monthly basis. Where there was no recorded data, the respondents were encouraged to estimate the monthly average quantity of that particular activity.

\subsection{Emission Factors Identifications}

Emission factors (EF) are critical in carbon footprint studies because they facilitate the calculation of GHG emissions by multiplying the amount of an activity associated with the release of the particular pollutant, expressed in their original internationally recognized units and converted into kilograms of carbon dioxide equivalent $\left(\mathrm{kgCO}_{2} \mathrm{eq}\right)$. Carbon dioxide equivalent $\left(\mathrm{CO}_{2} \mathrm{e}\right)$ is a universal unit of measurement that allows various greenhouse gases to be expressed as a single number based on their GWP per one unit of carbon dioxide (Brander \& Davis, 2012). Several countries have developed their national EF for estimating national emissions, however, South Sudan has not developed its own EFs. In identifying the emission factors to be used in this study, several reference sources were consulted including the Department for Environment, Food and Rural Affairs, DEFRA (2019) and IPCC (2006) among other published studies as indicated in Table 2.

Table 1. Emissions types and description of sources considered in the Carbon Footprint indicator estimation.

\begin{tabular}{cl}
\hline Emission Type & Description \\
\hline Scope 1 & Direct emissions from sources under the control of the entity within its organizational boundaries \\
Scope 2 & $\begin{array}{l}\text { Indirect emissions from the entity's consumption of purchased electricity, heat, or steam linked to the national } \\
\text { energy mix }\end{array}$ \\
Scope 3 & Indirect emissions resulting from the entity's activities but from sources not under its control. \\
\hline
\end{tabular}


Table 2. List of conversion emission factors (EF) derived from DEFRA and the IPCC.

\begin{tabular}{cccccc}
\hline $\begin{array}{c}\text { Operational } \\
\text { Boundary }\end{array}$ & GHGs Sources & Unit & EF & EF Unit & Source \\
\hline Scope 1 & Diesel combustion & 1 & 2.677 & $\mathrm{kgCO}_{2}-\mathrm{e} / \mathrm{l}$ & $\mathrm{IPCC}, 2006$ \\
Scope 2 & - & - & - & - & - \\
& Solid waste & $\mathrm{kg}$ & 0.5865 & $\mathrm{kgCO}_{2}-\mathrm{e} / \mathrm{M}^{3}$ & DEFRA, 2019 \\
Scope 3 & Wastewater & $\mathrm{M}^{3}$ & 0.708 & $\mathrm{kgCO}_{2}-\mathrm{e} / \mathrm{M}^{3}$ & DEFRA, 2019 \\
& Water supply and use & $\mathrm{M}^{3}$ & 0.344 & $\mathrm{kgCO}_{2}-\mathrm{e} / \mathrm{M}^{3}$ & DEFRA, 2019 \\
\hline
\end{tabular}

\subsection{Inventory Data Analysis}

\subsubsection{Data Related to Energy Generation}

The combustion of fossil fuels like diesel for power generation emits different pollutants into the environment. The electricity supply in Juba is exclusively self-generated using captive diesel generators installed within the hotel premises. Activity data related to energy generation take into account fuel consumed for electricity generation and running hotel cars for goods and services transportation. GHG emissions were calculated using the emission factor presented in Table 2.

\subsubsection{Data Related to Solid Waste}

The activity data related to municipal solid waste took into account the general waste generated by the hotel with unknown composition. These wastes go to the dumping sites and then pass through the process of open burning. The emission factor used was taken from DEFRA (2019) which considers the total amount of generated waste whose composition is not known. Municipal solid waste is a potential source for GHGs emissions including $\mathrm{CO}_{2}, \mathrm{CH}_{4}$, and $\mathrm{N}_{2} \mathrm{O}$ (Umar, 2021).

\subsubsection{Data for Hotel Water Consumption}

Water is an essential life-sustaining resource with a high ecological and social value as well as a driver for sustainable development. The hotel sector consumes a huge amount of water for its daily operations, including kitchens and restaurants, laundry, guestrooms, and swimming pools. Yet in most developing countries, its acquisition is very expensive for the hotels as a large amount of it is bought from private tankers owners and having intense energy use and GHG emissions implications. The data inventory analysis of water use focused on GHG emissions associated with water withdrawal, storage, and distribution. Since there were no filed records for water consumption in most of the assessed hotels, a monthly average figure for the volume of water was estimated by the respondents.

\subsubsection{Data Related to Wastewater}

Juba has currently no wastewater treatment plant. The wastewater from the hotel rooms and kitchens flows into a decentralized septic tank within each hotel premises. When the septic tanks get full, the contents are exhausted and disposed of in designated pits in the outskirt of Juba city. This study recorded the volume of wastewater generated by each hotel for a period of one month to faci- 
litate GHG emissions analysis. Wastewater is a potential source of methane $\left(\mathrm{CH}_{4}\right)$, nitrous oxide $\left(\mathrm{N}_{2} \mathrm{O}\right)$ emissions, and carbon dioxide $\left(\mathrm{CO}_{2}\right)$. Despite the assertion of Griffith et al., (2009); Law et al., (2013); and Chai et al., (2015) for the underestimation of fossil $\mathrm{CO}_{2}$ emissions from wastewater in all GHG emissions reporting, IPCC recommends that $\mathrm{CO}_{2}$ emissions from wastewater should not be considered when reporting national total emissions because of its biogenic origin. On this note, this study focused only on $\mathrm{CH}_{4}$ and $\mathrm{N}_{2} \mathrm{O}$ emissions.

\subsection{GHG Emission Quantification}

GHG emissions of the twenty-seven hotels were quantified based on scopes 1 and 3 indicated in Table 2 because there was no relevant data for scope 2 at the time of data collection as stated earlier. As per the guidelines provided by IPCC, the emission of each GHGs is calculated by multiplying the activity data associated with the release of the particular gas by its corresponding emission factor, which is commonly used internationally according to Equation (1). In this study, the quantification process followed the procedure used by Abeydeera and Karunasena (2019a), focusing on three greenhouse gases including $\mathrm{CO}_{2}, \mathrm{CH}_{4}$, and $\mathrm{N}_{2} \mathrm{O}$, using Equations (1)-(4) respectively. The emission resulting from water consumption was calculated according to Equation (5), meanwhile, those from nonhazardous solid waste and wastewater were calculated using Equations (6) and (7) respectively.

$$
\begin{gathered}
G H G\left(\mathrm{~kg} \mathrm{CO}_{2}-\mathrm{e}\right)=A D \times E F \\
E_{\mathrm{CO}_{2}}^{C}=\sum_{f=1}^{f=F} \sum_{t=1}^{t=T} A_{f . t} \times E F_{\left(\mathrm{CO}_{2}\right) f} \\
E_{\mathrm{CH}_{4}}^{C}=\sum_{f=1}^{f=F} \sum_{t=1}^{t=T} A_{f . t} \times E F_{\left(\mathrm{CH}_{4}\right) f} \times G_{\mathrm{CH}_{4}} \\
E_{\mathrm{N}_{2} \mathrm{O}}^{C}=\sum_{f=1}^{f=F} \sum_{t=1}^{t=T} A_{f . t} \times E F_{\left(\mathrm{N}_{2} \mathrm{O}\right) f} \times G_{\mathrm{N}_{2} \mathrm{O}} \\
E_{\mathrm{CO}_{2}}^{W C}=\sum_{t=1}^{t=T} A_{(W C) t} \times E F_{(W C) t} \\
E_{\mathrm{CO}_{2}}^{M S W}=\sum_{t=1}^{t=T} A_{(M S W) t} \times E F_{(M S W) t} \\
E_{\mathrm{CO}_{2}}^{W W}=\sum_{t=1}^{t=T} A_{(W W) t} \times E F_{(W W) t}
\end{gathered}
$$

\section{Equations Abbreviations}

$A D$ : Activity Data; EF: Emission Factor; GWP. Global Warming Potential; $A_{(W C) t}$ : Amount $\left(\mathrm{m}^{3}\right)$ of fresh water used in the $t$ period; $A_{(M S W) t}$ : Amount $(\mathrm{kg})$ of solid waste generated in the $t$ period; $A_{(W W) t}$ : Amount $\left(\mathrm{m}^{3}\right)$ of wastewater generated in the $t$ period; $A_{f . t}$ : Amount (l) of the $f$ type of fuel used in the $t$ period; $E F_{(M S W) t}$ : Emission factor of $\mathrm{CO}_{2}$ for the $t$ type of solid waste in the $t$ period; $E F_{(W C) t}:$ Emission factor for the use of fresh water in the $t$ period; $E F_{(W W) t}:$ Emission factor for wastewater management in the $t$ period; $E F_{\left(\mathrm{CH}_{4}\right) f}$ : Emission fac- 
tor of $\mathrm{CH}_{4}$ for the $f$ type of fuel; $E F_{\left(\mathrm{CO}_{2}\right)}$ : Emission factor of $\mathrm{CO}_{2}$ for the $f$ type of fuel; $E F_{\left(\mathrm{N}_{2} \mathrm{O}\right) f}$ : Emission factor of $\mathrm{N}_{2} \mathrm{O}$ for the $\mathrm{f}$ type of fuel; $G_{\mathrm{CH}_{4}}$ : Global warming potential of $\mathrm{CH}_{4}$;

$G_{\mathrm{N}_{2} \mathrm{O}}$ : Global warming potential of $\mathrm{N}_{2} \mathrm{O} ;\left(E_{\mathrm{CO}_{2}}^{\mathrm{C}}\right)$ : Carbon emission due to consumption of fuel $f\left(E_{\mathrm{CH}_{4}}^{\mathrm{C}}\right)$ : Methane emission due to consumption of fuel $f$; $\left(E_{\mathrm{N}_{2} \mathrm{O}}^{C}\right)$ : Nitrous oxide emission due to consumption of fuel $f\left(E_{\mathrm{CO}_{2}}^{W C}\right)$ : Carbon emission due to use of fresh water; $\left(E_{\mathrm{CO}_{2}}^{\mathrm{MSW}}\right)$ : Carbon emission due to municipal solid waste; $\left(E_{\mathrm{CO}_{2}}^{W W}\right)$ : Emission due to wastewater management.

\subsection{GHGs Emission Reporting Mechanisms}

After determining the environmental impact of the hotel sector through the quantification of the total GHG emissions, a reporting mechanism for the hotels was proposed in order to ensure that the hotel sector is environmentally responsive in its operations. This is proposed in line with the requirements of the Kyoto Protocol on carbon reduction by countries and supported by the review of relevant literature.

\section{Results and Discussions}

\subsection{Carbon Footprint for the Hotels}

Despite playing a significant role in the national economy, the hotel industry is a major contributor of GHG emissions into the environment. In this study, a consumption-based carbon footprint of 27 hotels in Juba, South Sudan was evaluated. Figure 1(a) presents the different sources of GHG emissions classified as Scope 1, Scope 2, and Scope 3. The total greenhouse gas emissions that resulted from the activities of these hotels amounted to 14,624.9-ton $\mathrm{CO}_{2}$ eq on an annual basis. $98 \%$ of the GHGs were from scope 1 (i.e. fuel consumption) and $2 \%$ of the GHGs were from scope 3 sources. No data was recorded for Scope 2, which is related to emissions resulting from the use of purchased electricity (IPCC, 2006). As stated earlier in this study, Juba had no on-grid electricity supply when the study was conducted except onsite self-generation of electricity by each hotel using diesel generators. While scope 1 is solely emissions resulting from diesel combustion, 59\% of scope 3 emissions were wastewater-related emissions, 38\% were from withdrawing water, storage, and consumption and $3 \%$ emissions were from solid wastes. Figure 1(b) shows the detailed breakdown of the total emissions by source.

Through a detailed examination of the hotels' emission rates, the study revealed that there was no uniformity in the rates of GHG emissions across all hotels. For example, hotel 4 in Figure 2 has the highest emissions rate (1321.9-ton $\mathrm{CO}_{2}$ eq) while hotel 7 has the lowest emissions rate $\left(58.7 \mathrm{tCO}_{2} \mathrm{eq}\right)$ per annum. A detailed investigation into each hotel revealed a direct relationship between the class/services offered by the hotel and the corresponding carbon emissions. High-quality hotels emit more GHGs due to the varieties of services and accommodation capacity they offer than those classified as low quality having limited 


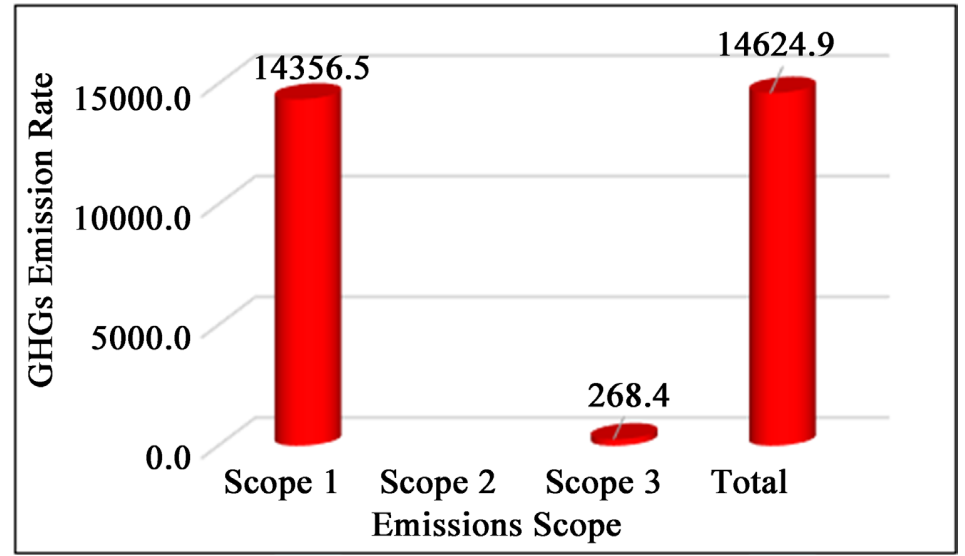

(a)

Total GHGs Emissions (tonCO2e)

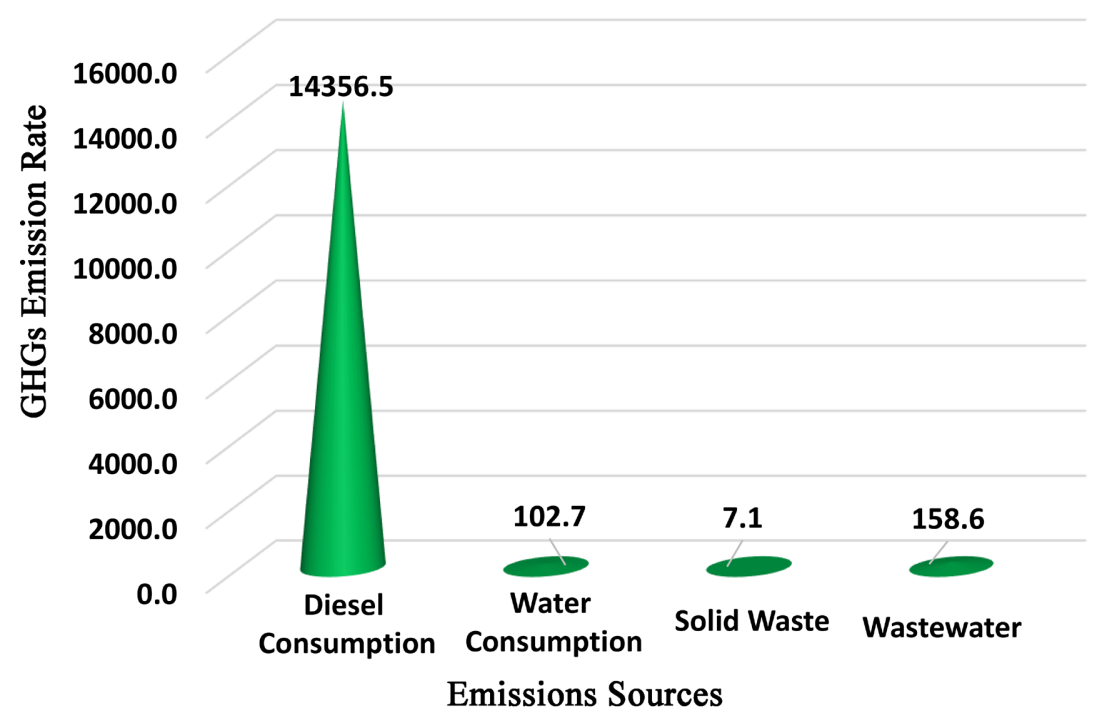

(b)

Figure 1. An annual GHG emissions by (a) scopes (b) source in tonCO $\mathrm{CO}_{2}$ eq.

services. This finding agrees with Abeydeera and Karunasena (2019a) who reported that in Sir Lanka, large hotels with high class have high emissions than guest houses and self-catering apartments because of the extra facilities such as restaurants, bars, SPAs, and swimming pools which generate more wastes and consume more energy. Figure 2 shows the comparison of the different emissions levels of each hotel with a vertical average emission level of which, a total of 11 hotels have surpassed.

\subsubsection{Energy Generation Related GHG Emissions}

Energy production and consumption is the major source of greenhouse gas emissions that results from the combustion of fossil fuel like oil, coal and natural gas. Globally, about $40 \%$ of the carbon emissions are associated with energy production (Abdallah \& El-Shennawy, 2013), and in Juba, electricity is self-generated using diesel generators. According to Goldemberg et al., (2000), diesel generators 
1400.0

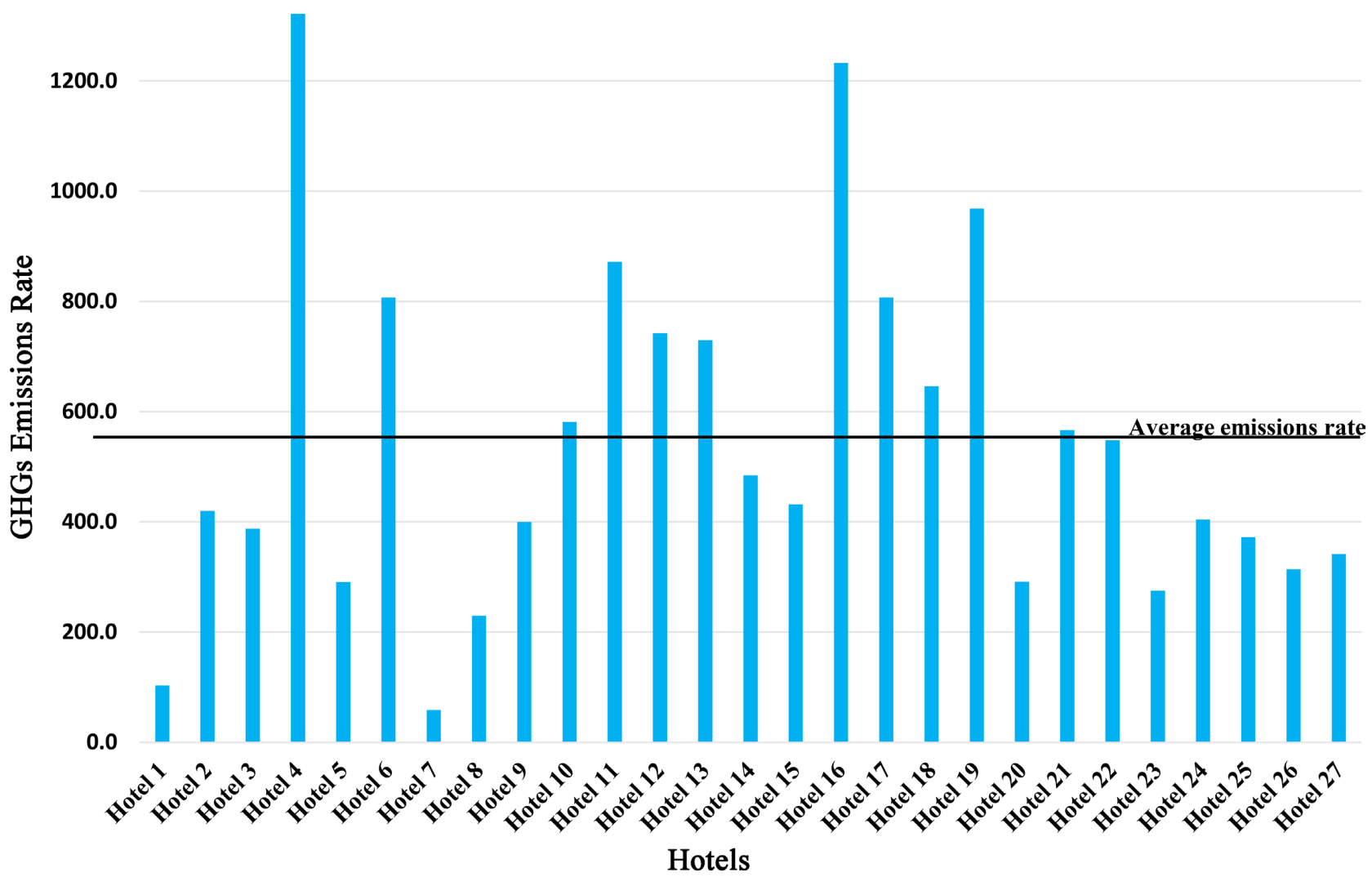

Figure 2. Levels of GHG emissions by hotel.

are still the main choice for electricity generation in the developing world due to their convenience and low installation costs. Steinbuks and Foster (2010) further reported that more than $6 \%$ of the installed electricity generation capacity of Sub-Saharan Africa is based on diesel generators. In South Sudan, the World Bank (2013) recommended the use of diesel generators for electricity generation due to limited financial resources for South Sudan to develop the available renewable energy sources. Consequently, Mozersky and Kammen, (2018) lamented that the absence of on-grid electricity in Juba city has culminated in a surge in the number of privately-owned diesel generator sets of varying capacity in the city. In this study, a total of 77 diesel generator sets with power capacity ranging from 30 to $950 \mathrm{kVA}$ and running age of 1 to 10 years old were recorded. The combustion of diesel emits dangerous pollutants such as carbon dioxide $\left(\mathrm{CO}_{2}\right)$, nitrogen oxide $(\mathrm{NOx})$, nitrous oxide $\left(\mathrm{N}_{2} \mathrm{O}\right)$, sulfur dioxide $\left(\mathrm{SO}_{2}\right)$, and methane $\left(\mathrm{CH}_{4}\right)$ into the air causing significant human health impacts. These pollutants are potential GHGs that are responsible for global warming and changes in climatic patterns.

Hotels' energy use intensity (EUI) is extremely high and varies with the hotel's geographical locations. Yao et al., (2015) reported that hotels located in hot areas consume more electricity compared to those in cold areas. Such energy consumption rates culminate in the emission of a large amount of GHGs into the 
environment. In this study, for instance, the annual energy generation and consumption-related emissions is $14,356.5$ tonCO $\mathrm{C}_{2}$ eq. As a country depending entirely on diesel-fired electricity, it is undoubted that the hotel and accommodation sector is one of the leading GHGs emitter in South Sudan after the agriculture sector. With the growing demand for hotel services in Juba, diesel-fired electricity-related GHG emissions will continue to increase exponentially due to hotels' operational expansion without the integration of sustainability aspects.

\subsubsection{Solid Waste Related Emissions}

Solid wastes are potential contributors to global warming and climate change through greenhouse gases emission into the environment (Umar, 2021). Hotels are important sources of waste generation with adverse impacts on the environment (Mensah, 2020; Guidoni et al., 2018). According to the Juba City Council, the body responsible for the governance of the city, Juba generates an estimated 3240 metric tons of solid waste per day, of which organic matter constitutes the largest portion and the hotel industry has a significant contribution. However, the effective management of solid waste remains a challenge for the local authorities.

In this study, the total GHG emissions from all generated solid waste by the hotels amounted to 7.1 tons $\mathrm{CO}_{2}$ eq/year. This amount is however questionable given the available body of literature regarding hotels' solid waste generation and the corresponding emissions. According to Trung and Kumar (2005), a typical hotel guest waste generation ranges from 0.4 to $17 \mathrm{~kg} / \mathrm{per}$ day. In this context, it is undeniable that the amount of solid waste in this study represents a small fraction of the actual solid waste related GHGs emitted by the hotels in Juba. During the assessment, it was observed that hotels in Juba do not have any form of waste management system and records. The solid wastes they generate are often collected and then transported to an open dumping site where incineration takes place and toxic gases are emitted into the environment. An effective hotel waste recording is a good management trajectory for improving the sector and moving it towards developing sustainable solutions such as reduce, reuse, and recycle (3Rs). This practice of solid waste management is feasible because an estimated $30 \%$ of the hotel's solid waste can be sorted, reused, recycled, or recovered (Chaabane et al., 2018). Thus, hotels in Juba could improve their waste management practice through proper record keeping of the amount and the composition of the solid waste they generate as a foundational step towards mainstreaming sustainability into the sector and reducing carbon emissions.

\subsubsection{Water Use and Wastewater Related Emissions}

Water is the most essential resource with a high social and ecological value used in large quantities in the hotel industry. This consumption is however contextual, depending on climatic factors, seasonality, hotel size, design, and age (Cole 
et al., 2020). Studies have shown that the per capita use of water by hotel users is higher than that of the local residentials and this varies substantially in developed and developing countries as well as on the basis of the hotel standard with luxurious hotels consuming more (Becken, 2014; Tirado et al., 2019). On average, the consumption level in a European hotel, for instance, is 394 liters/person/ night, 313 liters in Australia and New Zealand while in developing country like Barbados is 839 liters (Mclennan et al., 2017; Charara et al., 2011). In Juba-South Sudan, the consumption is significant and varies with the hotel's standard and size. This variation agrees with Gössling (2015) who reported that luxurious hotels with high standards consume more water than those categorized as low standards in the tourism sector.

Given the high-water consumption rate, a large quantity of wastewater is also generated as a result of the hotels' daily activities. Unlike in most urban settings with large-scale centralized wastewater treatment plants, Juba relies entirely on on-site septic tanks that retain both dense, settled sludge and less dense, flocculent waste. Previous studies have documented substantial evidence for the emission of GHGs such as $\mathrm{CH}_{4}, \mathrm{CO}_{2}$, and $\mathrm{N}_{2} \mathrm{O}$ from conventional septic tanks (Diaz-Valbuena et al., 2011). A hotel's GHG emission from water consumption and associated wastewater is a considerable contributor to the carbon inventory of individual sector. Using DEFRA (2019) emission factor for the quantification of GHGs emissions, this study found that the hotels' carbon footprint related to water management is 261.3 ton $\mathrm{CO}_{2} \mathrm{eq}$, of which 102.7 ton $\mathrm{CO}_{2} \mathrm{eq}$ is from water consumption and 158.6 ton $\mathrm{CO}_{2}$ eq from wastewater. As reported by Abeydeera and Karunasena (2019a), luxurious hotels offering a range of services to guests have higher emissions than non-luxurious ones which directly correspond with the volume of water consumed and wastewater generated.

\subsection{GHG Emissions Reporting}

Hotels GHGs emission reporting has gained recognition as a key indicator of environmental sustainability. As part of corporate social responsibility (CSR), companies are expected to disclose information regarding their environmental performance through emissions reporting to prove their transparency and accountability to national policies. There is now consensus in the scholarship that companies with good environmental performance and involvement in environmental conservation activities including consistent emissions reporting have a good reputation, increased value, and stand out as leaders in advancing sustainable development (Solikhah et al., 2021). Nevertheless, none of the 27 hotels has ever recorded its carbon emissions or reported environmental performance.

As a new signatory to UNFCCC, this study also found no existing national GHG emission reporting guidelines to facilitate emissions reporting in line with the requirements of the convention. The absence of existing reporting guidelines means that accurate and sector specific GHG emissions in the country have not 
been determined. In this study, we propose an emission reporting framework as a complementary to the framework by Abeydeera and Karunasena (2019b) with an institutional design perspective to help hotels develop a simplified emission reporting system with elements of promoting compliance with existing global requirements.

\section{Proposed GHG Emissions Reporting Framework for Hotels in Juba}

When establishing a GHG emission reporting mechanism, it is essential to identify specific operational aspects while taking into account the three scopes from which emissions data is to be collected. The reporting process is a combination of different steps that should be followed closely to implement a successful reporting mechanism. Based on the literature review coupled with the study findings, we triangled the steps involved in GHG emission reporting process into three main setups including institutional, technical and monitoring and verifications setups which is being referred to as a framework (Figure 3). Each setup of the framework provides a list of practical activities to guide hotels in developing a reporting mechanism. Using this framework, the GHG emissions of the hospitality industry can be recorded under the three scopes (i.e. direct emissions, indirect emissions and other indirect emissions). These have been derived from the literature review which showed that data related to GHG emissions shall be collected under three main scopes and should follow a sequential process to avoid missing important data and evaluation process.

\section{Monitoring and Verification Setup 3}

$>$ Determine national reporting requirements

$>$ Verify data sources and EF

$>$ Verify report against requirements

$>$ Submit report to relevant national authorities

$>$ Take actions to reduce GHG emission

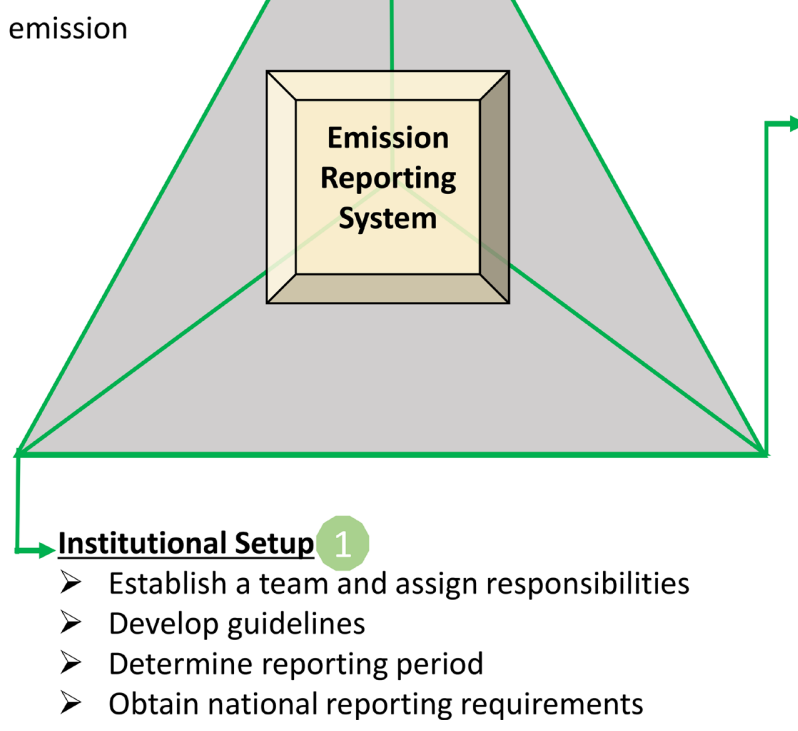

Technical Setup 2

Build team capacity

$>$ Determine data sources

$>$ Data collection

$>$ Establish emission factors (EF)

Calculate emissions

$>$ Develop emission report

Figure 3. A proposed framework for developing hotels' GHG emission reporting system. 
Using the outlined three stages of the framework presented in Figure 3, hotels can establish their emission reporting system that is simple to implement and complies with relevant standards. This framework also integrates essential elements of environmental human resources development (Piwowar-Sulej, 2021) currently missing in South Sudan through building staff capacity on general environmental management and GHG emission reporting procedures as well as establishing collaborative partnerships with the relevant national institutions concerned with emission reporting. It further institutionalizes an effective monitoring and verification system to ensure compliance with both national and institutional operational standards.

\section{Conclusion and Recommendations}

This study was conducted in Juba-South Sudan focusing on analyzing the environmental performance of hotels operation, regarding their carbon emissions status and GHGs emission reporting. GHG emissions from twenty-seven hotels were quantified in terms of carbon dioxide equivalents. The findings showed that hospitality industry is responsible for a large amount of GHGs emission amounting to 14,624.9-ton $\mathrm{CO}_{2}$ eq/year, with diesel consumption for electricity generation being the main source of hotels' GHG emissions. Other sources of hotels' GHG emissions include water consumption, wastewater and solid waste. However, concerns were noted on the solid waste management practices of the hotels since the reported amount does not agree with the available literature regarding hotels' per capita waste generation. Using the method adopted in this study, it was further identified that the carbon footprints of the other hotels that were not captured in this study can also be calculated to achieve a comprehensive record for establishing representative emission benchmarks that would help monitor and improve the carbon footprints of hotels.

The study found that South Sudan lacks relevant guidelines to encourage hotels operating in the country to prioritize environmental protection in their operations. This has created reluctance among hoteliers in integrating environmental management practices and proper reporting on the hotels' environmental performance. Hence, this study proposed a framework whose adoption by the hotels' management would integrate environmental education into the hotel industry through capacity building initiatives, promote collaborations with the national authorities, and encourage hotels to periodically report on their GHG emissions.

As supported by existing literature on hotels' GHG emissions potential, addressing issues of hotels' carbon footprint has become an important aspect of initiating sustainability in the industry to impact the global carbon emission reduction effort. We, therefore, conclude that the hospitality sector in South Sudan be included among the priority sectors targeted for GHG emissions reduction and that the government needs to develop national emission reporting guidelines. The GHG emissions reporting framework proposed in this study could be 
employed as a guide for developing a comprehensive national reporting mechanism for South Sudan to secure the health of its environment and people from the negative impacts of GHG emissions while achieving several Sustainable Development Goals.

In line with the Kyoto Protocol's targets for GHG emission reduction, we have identified potential reduction strategies for the hospitality industry including adoption of alternative energy sources like solar energy, mainstreaming climate change precautions in designing buildings, implementing environmental and sustainability practices and complying with or enforcing national environmental regulatory measures that can facilitate transition to sustainability practices that conserve the environment while improving revenues. However, we recommend that further research to examine the applicability of these strategies in South $\mathrm{Su}$ dan's context be pursued. We also recommend additional studies to quantify greenhouse gases from cooling appliance within the hospitality industry as well as emissions from other growing sectors like the transportation.

\section{Acknowledgements}

We acknowledge the support from Open Society Foundation and Central European University Foundation for funding the study. We also appreciate the courage of the respondents who despite the sensitivity of research in Juba South Sudan were able to provide crucial data.

\section{Conflicts of Interest}

The authors declare no conflicts of interest regarding the publication of this paper.

\section{References}

Abdallah, L., \& El-Shennawy, T. (2013). Reducing Carbon Dioxide Emissions from Electricity Sector Using Smart Electric Grid Applications. Journal of Engineering, 2013, Article ID: 845051. https://doi.org/10.1155/2013/845051

Abeydeera, L. H. U. W., \& Karunasena, G. (2019a). Carbon Emissions of Hotels: The Case of the Sri Lankan Hotel Industry. Buildings, 9, Article No. 227. https://doi.org/10.3390/buildings9110227

Abeydeera, L. H. U. W., \& Karunasena, G. (2019b). Greenhouse Gas Emission Reporting Mechanism for Hotel Industry: A Case of Sri Lanka. International Journal of Environmental Sciences and Natural Resources, 20, Article ID: 556042. https://doi.org/10.19080/IJESNR.2019.20.556042

Abeydeera, U. W., Hewage, L., Wadu Mesthrige, J., \& Samarasinghalage, T. I. (2019). Global Research on Carbon Emissions: A Scientometric Review. Sustainability, 11, Article No. 3972. https://doi.org/10.3390/su11143972

Aroonsrimorakot, S., Yuwaree, C., Arunlertaree, C., Hutajareorn, R., \& Buadit, T. (2013). Carbon Footprint of Faculty of Environment and Resource Studies, Mahidol University, Salaya Campus, Thailand. APCBEE Procedia, 5, 175-180.

https://doi.org/10.1016/j.apcbee.2013.05.031

Becken, S. (2014). Water Equity—Contrasting Tourism Water Use with That of the Local 
Community. Water Resources and Industry, 7, 9-22.

https://doi.org/10.1016/j.wri.2014.09.002

Brander, M., \& Davis, G. (2012). Greenhouse Gases, $\mathrm{CO}_{2}, \mathrm{CO}_{2}$ e, and Carbon: What Do All These Terms Mean? Econometrica, White Papers.

Chaabane, W., Nassour, A., \& Nelles, M. (2018). Solid Waste Management Key Indicator Development for Hotels: A Tunisian Case Study Analysis. Recycling, 3, Article No. 56. https://doi.org/10.3390/recycling3040056

Chai, C., Zhang, D. W., Yu, Y. L., Feng, Y. J., \& Wong, M. S. (2015). Carbon Footprint Analyses of Mainstream Wastewater Treatment Technologies under Different Sludge Treatment Scenarios in China. Water, 7, 918-938. https://doi.org/10.3390/w7030918

Charara, N., Cashman, A., Bonnell, R., \& Gehr, R. (2011). Water Use Efficiency in the Hotel Sector of Barbados. Journal of Sustainable Tourism, 19, 231-245. https://doi.org/10.1080/09669582.2010.502577

Cingoski, V., \& Petrevska, B. (2018). Making Hotels More Energy Efficient: The Managerial Perception. Economic Research-Ekonomska Istraživanja, 31, 87-101. https://doi.org/10.1080/1331677X.2017.1421994

Cole, S. K. G., Ma, Y., \& Sandang, Y. (2020). “Tourism, Water, and Gender”-An International Review of an Unexplored Nexus. WIREs Water, 7, e1442. https://doi.org/10.1002/wat2.1442

DEFRA (2019). Conversion Factors: Condensed Set (for Most Users). https://www.gov.uk/government/publications/greenhouse-gas-reporting-conversion-fa ctors-2019

Diaz-Valbuena, L. R., Leverenz, H. L., Cappa, C. D., Tchobanoglous, G., Horwath, W. R., \& Darby, J. L. (2011). Methane, Carbon Dioxide, and Nitrous Oxide Emissions from Septic Tank Systems. Environmental Science and Technology, 45, 2741-2747. https://doi.org/10.1021/es1036095

Erickson, P., Allaway, D., Lazarus, M., \& Stanton, E. A. (2012). A Consumption-Based GHG Inventory for the US State of Oregon. Environmental Science and Technology, 46, 3679-3686. https://doi.org/10.1021/es203731e

Eskerod, P., Hollensen, S., Morales-Contreras, M. F., \& Arteaga-Ortiz, J. (2019). Drivers for Pursuing Sustainability through IoT Technology within High-End Hotels-An Exploratory Study. Sustainability, 11, Article No. 5372. https://doi.org/10.3390/su11195372

Filimonau, V., Dickinson, J., Robbins, D., \& Huijbregts, M. A. (2011). Reviewing the Carbon Footprint Analysis of Hotels: Life Cycle Energy Analysis (LCEA) as a Holistic Method for Carbon Impact Appraisal of Tourist Accommodation. Journal of Cleaner Production, 19, 1917-1930. https://doi.org/10.1016/j.jclepro.2011.07.002

Fujimori, S., Hasegawa, T., Takahashi, K., Dai, H., Liu, J. Y., Ohashi, H., \& Hijioka, Y. (2020). Measuring the Sustainable Development Implications of Climate Change Mitigation. Environmental Research Letters, 15, Article ID: 085004. https://doi.org/10.1088/1748-9326/ab9966

Gao, T., Liu, Q., \& Wang, J. P. (2014). A Comparative Study of Carbon Footprint and Assessment Standards. International Journal of Low-Carbon Technologies, 9, 237-243. https://doi.org/10.1093/ijlct/ctt041

GHG Protocol (2020). Greenhouse Gas Protocol. https://ghgprotocol.org

Goldemberg, J., Reddy, A. K. N., Smith, K. R., \& Williams, R. H. (2000) Rural Energy in Developing Countries. In J. O. Goldemberg (Ed.), World Energy Assessment (pp. 368-389). United Nations Development Programme. 
Gössling, S. (2015). New Performance Indicators for Water Management in Tourism. Tourism Management, 46, 233-244. https://doi.org/10.1016/j.tourman.2014.06.018

Griffith, D. R., Barnes, R. T., \& Raymond, P. A. (2009). Inputs of Fossil Carbon from Wastewater Treatment Plants to US Rivers and Oceans. Environmental Science and Technology, 43, 5647-5651.

Güereca, L. P., Torres, N., \& Noyola, A. (2013). Carbon Footprint as a Basis for a Cleaner Research Institute in Mexico. Journal of Cleaner Production, 47, 396-403. https://doi.org/10.1016/j.jclepro.2013.01.030

Guidoni, L. L. C., Peruchin, B., Corrêa, L. B., Marques, R. V., Vieira, L. A., Siqueira, T. M., \& Corrêa, É. K. (2018). Solid Waste Generation in a Hotel Event Service. Revista Internacional de Contaminación Ambiental, 34, 237-247. https://doi.org/10.20937/RICA.2018.34.02.05

Hertwich, E. G., Ali, S., Ciacci, L., Fishman, T., Heeren, N., Masanet, E., \& Wolfram, P. (2019). Material Efficiency Strategies to Reducing Greenhouse Gas Emissions Associated with Buildings, Vehicles, and Electronics-A Review. Environmental Research Letters, 14, Article ID: 043004. https://doi.org/10.1088/1748-9326/ab0fe3

IPCC (2006). 2006 Guidelines for National Greenhouse Gas Inventories. https://www.ipcc-nggip.iges.or.jp/public/2006gl/

Kennedy, C., \& Lindsey, R. (2015). What's the Difference between Global Warming and Climate Change? National Oceanic and Atmospheric Administration.

https://www.climate.gov/news-features/climate-qa/whats-difference-between-global-w arming-and-climate-change

Kumari, L. M. T., Kulatunga, U., Madusanka, N., \& Jayasena, N. (2018). Embodied Carbon Reduction Strategies for Buildings. In R. Dissanayake, \& P. Mendis (Eds.), International Conference on Sustainable Built Environment (pp. 295-308). Springer. https://doi.org/10.1007/978-981-13-9749-3 28

Laroui, F., Tellegen, E., \& Tourilova, K. (2004). A Flexibility Mechanism of the Kyoto Protocol-First Explorations of JI between the EU and Russia. Environmental Sciences, 1, 168-200.

Larsen, H. N., Pettersen, J., Solli, C., \& Hertwich, E. G. (2013). Investigating the Carbon Footprint of a University-The Case of NTNU. Journal of Cleaner Production, 48, 39-47. https://doi.org/10.1016/j.jclepro.2011.10.007

Law, Y., Jacobsen, G. E., Smith, A. M., Yuan, Z., \& Lant, P. (2013). Fossil Organic Carbon in Wastewater and Its Fate in Treatment Plants. Water Research, 47, 5270-5281. https://doi.org/10.1016/j.watres.2013.06.002

Lemi, L. D. M., \& LaBelle, M. C. (2020). Co-Supplying the National Grid: An Assessment of Private Off-Grid Electricity Generation in Juba-South Sudan. American Journal of Electrical Power and Energy Systems, 9, 47-59. https://doi.org/10.11648/j.epes.20200903.12

Loyarte-López, E., Barral, M., \& Morla, J. C. (2020). Methodology for Carbon Footprint Calculation towards Sustainable Innovation in Intangible Assets. Sustainability, 12, Article No. 1629. https://doi.org/10.3390/su12041629

Mclennan, C. L. J., Becken, S., \& Stinson, K. (2017). A Water-Use Model for the Tourism Industry in the Asia-Pacific Region: The Impact of Water-Saving Measures on Water Use. Journal of Hospitality and Tourism Research, 41, 746-767. https://doi.org/10.1177/1096348014550868

Mensah, I. (2020). Waste Management Practices of Small Hotels in Accra: An Application of the Waste Management Hierarchy Model. Journal of Global Business Insights, 5, 33-46. https://doi.org/10.5038/2640-6489.5.1.1081 
Montoya-Torres, J. R., Gutierrez-Franco, E., \& Blanco, E. E. (2014). Conceptual Framework for Measuring Carbon Footprint in Supply Chains. Production Planning and Control, 26, 265-279.

Mozersky, D., \& Kammen, D. M. (2018). South Sudan's Renewable Energy Potential. In L. Biong, D. Kuol, \& S. Logan (Eds.), The Struggle for South Sudan: Challenges of Security and State Formation (pp. 243-261). I.B. Tauris. https://doi.org/10.5040/9781788316361.ch-013

Nauclér, T., \& Enkvist, P. A. (2009). Pathways to a Low-Carbon Economy: Version 2 of the Global Greenhouse Gas Abatement Cost Curve. McKinsey \& Company.

Pablo-Romero, M. P., Sánchez-Braza, A., \& Sánchez-Rivas, J. (2017). Relationships between Hotel and Restaurant Electricity Consumption and Tourism in 11 European Union Countries. Sustainability, 9, Article No. 2109. https://doi.org/10.3390/su9112109

Padilla-Rivera, A., Amor, B., \& Blanchet, P. (2018). Evaluating the Link between Low Carbon Reductions Strategies and Its Performance in the Context of Climate Change: A Carbon Footprint of a Wood-Frame Residential Building in Quebec, Canada. Sustainability, 10, Article No. 2715. https://doi.org/10.3390/su10082715

Peters, G. P., Marland, G., Le Quéré, C., Boden, T., Canadell, J. G., \& Raupach, M. R. (2012). Rapid Growth in $\mathrm{CO}_{2}$ Emissions after the 2008-2009 Global Financial Crisis. Nature Climate Change, 2, 2-4. https://doi.org/10.1038/nclimate1332

Piwowar-Sulej, K. (2021). Environmental Strategies and Human Resource Development Consistency: Research in the Manufacturing Industry. Journal of Cleaner Production, 330, Article ID: 129538. https://doi.org/10.1016/j.jclepro.2021.129538

Ricaurte, E. (2011). Developing a Sustainability Measurement Framework for Hotels: Toward an Industry-Wide Reporting Structure. The Center for Hospitality Research, 11, 6-30.

Solikhah, B., Wahyuningrum, I. F. S., Yulianto, A., Sarwono, E., \& Widiatami, A. K. (2021). Carbon Emission Report: A Review Based on Environmental Performance, Company Age and Corporate Governance. IOP Conference Series: Earth and Environmental Science, 623, Article ID: 012042. https://doi.org/10.1088/1755-1315/623/1/012042

Steinbuks, J., \& Foster, V. (2010). When Do Firms Generate? Evidence on In-House Electricity Supply in Africa. Energy Economics, 32, 505-514. https://doi.org/10.1016/j.eneco.2009.10.012

Stewart, C. J., \& Cash, W. B. (2008). Interviewing: Principles and Practices. Boston, MA: McGraw-Hill.

Tirado, D., Nilsson, W., Deyà-Tortella, B., \& García, C. (2019). Implementation of Water-Saving Measures in Hotels in Mallorca. Sustainability, 11, Article No. 6880. https://doi.org/10.3390/su11236880

Trung, D. N., \& Kumar, S. (2005). Resource Use and Waste Management in Vietnam Hotel Industry. Journal of Cleaner Production, 13, 109-116.

https://doi.org/10.1016/j.jclepro.2003.12.014

Umar, T. (2021). Estimating Greenhouse Gas (GHG) Emissions from Municipal Solid Waste (MSW) in Oman Using Different Frameworks. The Journal of Solid Waste Technology and Management, 47, 332-348. https://doi.org/10.5276/JSWTM/2021.332

USAID (2016). Climate Change Risk Profile-South Sudan. https://www.climatelinks.org/sites/default/files/asset/document/2016\%20CRM\%20Fact \%20Sheet\%20-\%20South\%20Sudan 0.pdf

Wang, X., Wu, N. Q., Qiao, Y., \& Song, Q. B. (2018). Assessment of Energy-Saving Practices of the Hospitality Industry in Macau. Sustainability, 10, Article No. 255. 
https://doi.org/10.3390/su10010255

Wiedmann, T., Wood, R., Minx, J. C., Lenzen, M., Guan, D., \& Harris, R. (2010). A Carbon Footprint Time Series of the UK-Results from a Multi-Region Input-Output Model. Economic Systems Research, 22, 19-42. https://doi.org/10.1080/09535311003612591

World Bank (2013). South Sudan-Electricity Sector Strategy Notes (ESSN) (English). Washington DC: World Bank.

http://documents.worldbank.org/curated/en/354201468102894108/South-Sudan-Electr icity-sector-strategy-note-ESSN

Yao, Z. X., Zhuang, Z., \& Gu, W. (2015). Study on Energy Use Characteristics of Hotel Buildings in Shanghai. Procedia Engineering, 121, 1977-1982.

https://doi.org/10.1016/j.proeng.2015.09.195

Yoon, Y., Yang, M., \& Kim, J. (2018). An Analysis of CO2 Emissions from International Transport and the Driving Forces of Emissions Change. Sustainability, 10, Article No. 1677. https://doi.org/10.3390/su10051677

Zheng, J. J., \& Suh, S. (2019). Strategies to Reduce the Global Carbon Footprint of Plastics. Nature Climate Change, 9, 374-378. https://doi.org/10.1038/s41558-019-0459-z 